\title{
Espaços digitais e a comunicação intercultural no ensino de inglês como língua adicional
}

\author{
Fátima de França Machado ${ }^{\mathrm{i}}$ \\ Viviane Caldasii
}

\section{RESUMO}

O ensino da língua inglesa vem ganhando novos propósitos e dimensões que reforçam a importância de uma abordagem intercultural (CORBETT, 2010), uma vez que esse idioma alcançou o status de língua global e os avanços da tecnologia facilitam cada dia mais a comunicação e a interação em redes de trocas plurais e multiculturais em espaços digitais. O objetivo central deste artigo é investigar brevemente o potencial de interações online em práticas interativas (SILVA, 2012) que contribuam para a formação integral do aluno como falante competente de uma língua internacional, como cidadão global.

Palavras-chave: Interculturalidade; Inglês como língua internacional; Tecnologia em ensino de LI; Descolonização do ensino de inglês; Cultura.

\begin{abstract}
Teaching English as an additional language has gained new purposes and dimensions thus reinforcing the importance of an intercultural approach (CORBETT, 2010) since this language has gained the status of a global language, and advances in technology have increasingly facilitated communication and interaction by enabling multicultural exchanges in digital spaces. The main goal of this article is to briefly investigate how online spaces offer a potential for interactive practices (SILVA, 2012) that contribute to helping the student to become a competent speaker of an international language as a global citizen.
\end{abstract}

Keywords: Interculturality; English as an International language; Technology in ELT; Decolonization in ELT; Culture.

\footnotetext{
${ }^{\text {i }}$ Especialista em Linguística Aplicada com Ênfase no Ensino de Inglês como Língua Adicional e cursando Mestrado em Estudos de Língua com Ênfase em Linguística (ambos na Universidade do Estado do Rio de Janeiro). | fatimamachado.rj@gmail.com | https://orcid.org/0000-0002-7974-2781

ii Especialista em Linguística Aplicada com Ênfase no Ensino de Inglês como Língua Adicional e cursando Mestrado em Estudos de Língua com Ênfase em Linguística (ambos na Universidade do Estado do Rio de Janeiro). | teachervivicaldas@gmail.com
} 


\section{INTRODUÇÃO}

Ao longo dos últimos anos, foi possível acompanhar como a evolução da tecnologia redesenhou as oportunidades de comunicação intercultural, assim como descrito por Corbett (2010). Além disso, a língua inglesa assume hoje um status de língua global, sendo amplamente usada nas relações econômicas e comerciais, tanto no âmbito acadêmico quanto nos espaços digitais. Isso leva o idioma a cruzar fronteiras, fazendo com que os falantes se aproximem de discursos globais e reinventem a vida no contexto local em seus cotidianos (Cf. MOITA-LOPES, 2008).

Ao relacionar essas questões, entende-se que as tecnologias digitais podem permitir um fluxo interativo em espaços online multiculturais plurilíngues. Esses espaços funcionam como um meio profícuo para momentos importantes na educação linguística, tais como: a negociação na construção de identidades, a criação de uma sensação de pertencimento a um mundo globalizado e interconectado, o exercício do ouvir e de se fazer ouvido e o de entender e se fazer entendido. Nesses ambientes, o status de língua internacional faz com que a língua inglesa seja uma ferramenta essencial para mediar e viabilizar interações e comunicações interculturais.

Ainda que o acesso a oportunidades para trocas interculturais tenha crescido com a difusão do uso da Internet, o sucesso de interações on-line com fins de aprendizagem depende de gerenciamento e planejamento por parte do professor. Dependendo do uso que se faz das tecnologias, meios e espaços digitais, poderá haver apenas uma transposição do meio, sem uma ressignificação das práticas e "o sucesso de aquisição de uma língua estrangeira depende da inserção do aprendiz em atividades de prática social da linguagem" (PAIVA, 2008, p.14).

Um dos desafios é conseguir estabelecer e monitorar uma comunidade on-line para tais trocas interculturais, considerando a disponibilidade de recursos tecnológicos e conectividade disponíveis, a segurança de tais ambientes, e além disso, o fator interculturalidade. Preparar os alunos para um intercâmbio entre pessoas de diferentes culturas usando a língua inglesa como instrumento e entendendo que embora estejam usando uma língua em comum, cada interlocutor acaba tendo percepções orientadas por pressupostos socioculturais distintos e que são pertinentes às suas próprias culturas (KAWACHI, 2011). 
Este trabalho pretende enriquecer o debate sobre a comunicação intercultural como forma de pensar e de promover, no âmbito do ensino de língua inglesa, a construção de discursos globais a partir da criação de novas oportunidades de ser, de conhecer e de se tornar, de olhar para si e para o outro. É importante que o desenho e o planejamento de atividades, materiais e aulas para o ensino de inglês como uma língua global se situe também no contexto local, abrindo espaço para desconstrução de estereótipos, de hierarquizações culturais e se aproximando de valores de tolerância e compreensão (ALMEIDA FILHO, 2002). Além disso, o cuidado com o trabalho comunicativo no eixo intercultural deve considerar que alguns alunos brasileiros podem apresentar resistência ao aprendizado do idioma e este sentimento pode estar relacionado ao fato de envolver suas identidades, relações de domínio e poder cultural e econômico com concepções conflitantes entre língua, sujeito e sociedade.

Outra questão contemplada é a da interatividade destacada em Silva (2010): o autor afirma que propostas interativas têm potencial para preparar os alunos para engajar-se em comunidades de prática, e que dessa maneira poderão se comunicar de forma efetiva. Além disso, interações on-line proporcionam vastos contextos e conteúdos para a aprendizagem. Logo, aproximar as práticas comunicativas das novas formas de interagir e de se comunicar - tão presentes no dia a dia dos alunos através das novas mídias, aplicativos e espaços on-line com toda sua dinamicidade, elasticidades espaço-temporal e possibilidades de encontros pluriculturais - contribui para o aperfeiçoamento e melhor uso das tecnologias de comunicação e informação no contexto do ensino de línguas em todo o seu potencial. Diante disso e amparando-se em uma breve revisão de estudos na área, cabe discutir a seguinte pergunta: Como desenvolver oportunidades viáveis de troca intercultural na prática comunicativa de inglês através das tecnologias digitais?

Desse modo, apresenta-se a organização deste estudo. Na primeira parte, são abordadas as questões interculturais e a dicotomia língua-cultura aliadas ao posicionamento do inglês no contexto global. Na sequência, o foco é em estudos que falem sobre a uso da Internet como espaço para comunicação, a interatividade com suas aplicações na sala de aula, o papel do aluno e professor e o letramento digital atrelado à prática comunicativa intercultural. No terceiro momento, há uma breve explicação da metodologia de pesquisa e, no quarto, a apresentação de exemplos encontrados na busca 
realizada por pontos de intersecção entre o trabalho da interculturalidade ao elencar experiências relatadas em outros estudos do uso de atividades interativas digitais que promovem acesso ao multicultural e possibilitam a prática da comunicação na língua alvo. Na última seção, as considerações não-finais indicam conclusões iniciais e sugestões de novos estudos mais aprofundados sobre o tema.

\section{O PAPEL DA LÍNGUA INGLESA E DAS QUESTÕES INTERCULTURAIS}

Este trabalho pretende pensar em momentos das aulas de inglês que trabalhem uma construção social e identitária integral, consciente e global através de atividades interculturais que usam a tecnologia e a Internet como ferramentas. Dessa maneira, para iniciar a reflexão sobre a temática deste trabalho, é importante discutir brevemente alguns conceitos acerca do status do inglês como língua internacional, problematizações relacionadas à língua e cultura e à abordagem intercultural.

\subsection{0 inglês como uma língua do mundo}

Uma comunicação efetiva entre participantes que não compartilhem a mesma língua materna demanda o uso de um código que seja comum a ambas as partes, ou seja, uma língua conhecida por todos os interlocutores envolvidos. Em tempos pósmodernos, a língua inglesa deixa de ser vista como língua estrangeira para atingir o status de língua global, internacional, do mundo e, sendo assim, de todos os que a falam (Cf. MOITA-LOPES, 2008; RAJAGOPALAN, 2009).

David Crystal (2003) estimava que aproximadamente um quarto da população mundial fosse fluente ou competente em inglês. Nos anos 2000, esse número representava por volta de 1,5 bilhão de pessoas. Esses números trazem, indiscutivelmente, novos significados para as relações de ensino-aprendizagem e, consequentemente, para a produção de materiais didáticos e elaboração de atividades uma vez que as interações usando o idioma inglês como forma de contato poderão acontecer com falantes de inglês como primeira língua ou entre membros de duas ou mais culturas distintas, ainda que nenhum deles tenha o inglês como língua materna. Os dados desse estudo mostram também que um a cada quatro falantes de inglês no mundo 
seria falante de outra língua. Isso não exclui a possibilidade de interações acontecerem com indivíduos que usam inglês como primeira língua, mas ressalta que a maioria das interações provavelmente irá ocorrer entre os que usam o inglês para possíveis interações em contextos de comunicação global.

É importante relacionar, no âmbito deste estudo, o papel que o inglês desempenha como língua internacional (ou língua global). Uma língua do "mundo" que vai ser usada em trocas interculturais, sendo que tais interações irão acontecer com frequência entre falantes de diferentes origens linguístico-culturais.

Kawachi e Lima (2015) reforçam que não há como ignorar que o estatuto do inglês como língua franca vem trazendo implicações importantes para o ensino de idiomas que carecem de uma nova conscientização do papel do idioma na comunicação demandando uma nova perspectiva sobre quais seriam os motivos para se aprender inglês e trazendo uma necessidade de se incorporar outras variedades do idioma ainda que não sejam faladas nos países em que é a primeira língua ou a língua materna. Tais considerações apontam que o foco educacional no ensino de línguas, e nas atividades e materiais que servem a esse propósito, precisam desmistificar o suposto Inglês Padrão/Norma Culta e focar na habilidade de negociar a diversidade, navegar por incertezas e instruir os alunos a se tornarem capazes de lidar com diferentes contextos e estilos comunicativos.

Assim, as aulas de língua inglesa podem ser desenvolvidas para reconhecer e reforçar a diversidade como uma característica determinante nas comunicações interculturais que usam o inglês como língua comum e que visam à formação de identidade individual, coletiva e global dos alunos.

\subsection{Sobre língua e cultura}

Kramsch $(1998$, p. 7) afirma que cultura e identidade estão relacionadas e que a cultura é construída a partir das interações estabelecidas historicamente:

Cultura consiste, precisamente, naquela dimensão histórica na identidade de um grupo. Essa visão diacrônica de cultura enfoca a maneira como um grupo social representa a si mesmo e outros por meio de suas produções materiais ao longo do tempo - seus alcances tecnológicos, seus monumentos, seus trabalhos de arte - que pontuam o desenvolvimento de sua identidade histórica. (Kramsch, 1998, p. 7) 
Considerando a definição supracitada, é preciso lembrar também que não podemos dissociar língua e cultura já que influenciam a nossa organização de sentidos e a nossa percepção de mundo. Ainda, segundo Rajagopalan (2003), uma língua está ligada diretamente à identidade de seu povo. Isso reafirma que a construção de uma identidade plural se entrelaça à valorização de aspectos linguístico-culturais.

Kawachi (2011) levanta a questão de que é muito comum, no ensino de inglês, referir-se à cultura através de exemplos relacionados a assuntos vinculados à arte, arquitetura, e geografia e conclui que, no ensino-aprendizagem de idiomas, o foco muitas vezes é direcionado a concepção de cultura como arte. Essas considerações reforçam as preocupações deste estudo que busca formas de trabalhar com questões interculturais mais abrangentes e que se relacionem com a interação.

Um enfoque cultural mais crítico e mais amplo, que englobe aspectos sociais, históricos e políticos e que não definam cultura por um viés superficial, em forma de curiosidades ou como "objeto estático, situado fora do tempo e do espaço" (BARBOSA, 2009, p. 2), é um movimento essencial ao tratarmos de uma língua usada globalmente, como visto na seção anterior. Sendo assim, não podemos ignorar aspectos de interculturalidade nas aulas de inglês como língua internacional, como uma forma de provocar impacto social e cultural e de ressignificar o papel do ensino de inglês como um ato político em busca de um possível futuro global mais inclusivo, mais tolerante e com mais equidade.

Retomando a posição do inglês como uma "língua de todos" (KUMARAVADIVELU, 2006) e entendendo o papel do falante ou aprendiz no contexto comunicativo global, é necessário garantir que a cultura local não seja negligenciada ou omitida com atividades pensadas não só para projetar um olhar para o outro, mas que também promovam um olhar para si mesmo e para a própria cultura a fim de interagir com o outro, como no modelo de Byram (apud CORBETT, 2010) acerca da competência comunicativa intercultural. Na visão do autor, essa competência diz respeito a conhecer a si mesmo e ao outro, saber como relacionar e interpretar significado, desenvolver pensamento crítico, saber como encontrar informação cultural e saber como relativizar a si mesmo e valorizar as atitudes e crenças do outro.

\subsection{Interculturalidade no ensino de inglês}


Interações interculturais podem ser identificadas na história a partir da vontade do ser humano de estabelecer relações em sociedade e em comunidade uns com os outros. Em um mundo globalizado, a necessidade de comunicação efetiva tem sido enfatizada cada vez mais. Com isso, o desenvolvimento da competência intercultural torna-se um quesito essencial para viver em sociedade e toda a diversidade que figura no século XXI.

Em abordagens mais tradicionais, o foco no ensino de questões culturais acaba se limitando a uma visão de cultura rasa, em forma de curiosidades sobre o outro que são apresentadas. Tais perspectivas deixam de cumprir com o principal objetivo do ensino pautado na interculturalidade que, segundo Almeida Filho (2002), seria nortear o aluno na cultura do outro e não apenas descrevê-la ou listar informações sobre ela. Mais que isso, uma abordagem intercultural preza não só pela variedade e diversidade cultural, mas também pela cultura do próprio aluno. Assim, a língua se torna uma ferramenta para exploração e mediação cultural (CORBETT, 2010).

Sobre essa questão, Moita-Lopes (1996) afirma que:

O ensino de línguas estrangeiras deve enfatizar que os estereótipos atribuídos
a cada povo, inclusive o nativo, não são absolutos, ou seja, nenhum povo é
desse ou daquele jeito. O ser humano é complexo e alguma variação mais
genérica de comportamento que possa existir não se deve a características
inerentes aos povos. (Moita Lopes, 1996, p. 32)

Mesmo em uma sociedade multissemiotizada e plural, o acesso à educação da maioria da população é restrito à educação hegemônica (ROCHA; MACIEL, 2013) e a busca por uma educação linguística democrática e cidadã precisa promover compreensão intercultural, contemplando diversidade e criticidade. Uma proposta intercultural tem potencial para promover reflexões que não se limitem apenas à cultura estrangeira com enfoque unicamente na língua-cultura alvo. O conhecimento da cultura local (a cultura dos alunos) é essencial para a compreensão, construção e negociação de sentidos e significados a partir da cultura do outro. Em Corbett (2010, p. 5) temos: "uma educação linguística intercultural começa com o pressuposto de que o contato entre culturas deve ser mutuamente enriquecedor para os indivíduos das comunidades envolvidas."

São diversos os autores que abordam a formação docente visando a uma sala de 
aula que seja vista como um espaço político de transformação social (KUMARAVADIVELU, 2006; 2008; MALDONADO-TORRES, 2010) e que advogam por um trabalho com a interculturalidade que ocorra de forma não-hierarquizada e inclusiva.

Uma compreensão intercultural faz com que "as pessoas se tornem cidadãos globais e locais responsáveis, equipados através da educação que recebem para viver e trabalhar juntos em um mundo interconectado" (ACARA apud. KALANTZIS et al, 2016). Os alunos irão desenvolver tal entendimento ao aprenderem a valorizar suas próprias culturas, línguas, crenças e valores e a cultura, a língua, as crenças e os valores do outro. Problematizar essa questão é essencial para garantir uma formação linguística cidadã que fomente uma participação social crítica.

\section{INTERCULTURALIDADE, INTERATIVIDADE E LETRAMENTO DIGITAL}

Nesta parte da pesquisa, o foco recai sobre a questão do uso das tecnologias digitais que possam permitir a prática da comunicação intercultural. Relaciona-se, então, ao enfoque em questões pertinentes à interculturalidade: o uso da Internet, o conceito de interatividade e o letramento digital.

\subsection{A internet como meio para comunicação intercultural}

A chegada e os avanços da Internet já redesenharam a comunicação intercultural para muitos alunos, uma vez que a rede amplia os espaços de circulação social. Aplicativos de mensagens instantâneas, e-mails, blogs, fóruns, Wikis e redes sociais tornaram a comunicação entre línguas e culturas mais acessível. A Web e o advento das redes sociais trazem oportunidades e canais para a comunicação interativa e instantânea com pessoas de diferentes culturas e partes do mundo, incluindo falantes de inglês como língua materna e falantes de outras línguas maternas que recorrem à língua inglesa como código comum nessas interações.

Além de ser fonte de informação sobre diferentes culturas e sociedades, Corbett (2010) relaciona a Internet à educação linguística intercultural e propõe exemplos de atividades que promovam a construção de comunidades interculturais virtuais para 
trocas online efetivas. $\mathrm{O}$ autor ainda considera que muitas das atividades podem ser adaptadas para o uso onde o acesso à Internet não seja viável.

\begin{abstract}
Atualmente os alunos possuem acesso a uma gama imensa de canais para comunicação instantânea e interativa com usuários de inglês do mundo todo. Nunca antes houve tantas oportunidades ricas para uso de linguagem 'autêntica' e para comparação de diferentes práticas culturais. (CORBETT, 2010, p.11)
\end{abstract}

As novas mídias são produtoras de cultura e detentoras de linguagens próprias e múltiplas. Não se pode ignorar, então, ao falar de língua e interculturalidade, que essa multiplicidade de linguagens está diretamente atrelada às tecnologias da informação e da comunicação, e a aplicação de recursos tecnológicos nos contextos educacionais. Há uma diversidade indiscutível de meios didáticos e de espaços interativos que permitem aos alunos, por exemplo, interagirem na língua alvo através de meios cada vez mais acessíveis para conexão online, como por exemplo, os smartphones e as redes sociais.

\title{
$2.2 \mathrm{O}$ conceito de interatividade
}

Silva (2010) discursa sobre as consequências da evolução tecnológica para a sociedade e, consequentemente, para a sala de aula. Antes, os indivíduos se comportavam como meros receptores de informações e não havia muito espaço para interação. A partir do acesso mais amplo à Internet e à Web 2.0, há uma reorganização das formas de comunicação, dos espaços e limites socioculturais, e da sala de aula que passa a apresentar novas demandas e expectativas dos alunos e um novo posicionamento do papel do professor.

Assim, o uso das tecnologias por si só não garante práticas necessariamente interativas caso o planejamento das sequências didáticas e atividades utilize o recurso digital apenas como uma ferramenta de entrega de conteúdo, como se substituísse o "meio" sem uma ressignificação e redesenho da prática pedagógica e das relações de ensino-aprendizagem.

O professor interrompe a tradição do falar/ditar, deixando de identificar-se com o contador de histórias, e adota uma postura semelhante à do designer de software interativo. Ele constrói um conjunto de territórios a serem explorados pelos alunos e disponibiliza coautoria e múltiplas conexões, permitindo que o aluno também faça por si mesmo. (SILVA, 2012, p. 23)

Sob essa perspectiva, o aluno deixa a postura de sujeito passivo, que recebe as 
instruções de um professor que se posicionaria como o único e principal detentor de informações e conteúdo. Há um novo significado no papel do professor que se torna um mediador na construção e na produção de conhecimento. Silva (2011) aponta algumas das alterações na função social do professor:

O docente não é mais aquele que segura o conhecimento absoluto e dogmático (que não permite questionamentos), mas aquele que estabelece a articulação entre o saber e o aluno. Nessa direção, o professor é alçado à condição de mediador, deixando de lado a postura de transmissor de conteúdos e, por conseguinte, assumindo o papel de orientador e de estimulador na construção social do conhecimento do aluno (Silva, 2011, p. 1)

Logo, atividades do eixo intercultural que explorem os meios e mídias digitais e coloquem o aluno em oportunidades de prática interativas potencialmente se desenvolverão perpassando as indicações de Silva (2011) para a promoção de uma sala de aula interativa. $\mathrm{O}$ autor sugere a demanda da participação-intervenção dos alunos como atuantes na construção do conhecimento e da comunicação; a oferta de informações através de redes de conexões que permitem liberdade de associações e significações; e o estímulo constante da expressão livre e plural em que haja respeito pelas diferenças abrindo espaço para o exercício da democracia.

\subsection{Letramento digital e interculturalidade: interseções}

Assim como as questões levantadas na seção anterior sobre os desdobramentos dos avanços tecnológicos para as formas de interação e comunicação, é importante considerar os impactos que se desvelam a partir de tais questões para as habilidades e competências necessárias para uma formação linguística efetiva a partir dos estudos sobre os letramentos.

Inicialmente, é importante definir letramento digital. Segundo Soares (2002, p. 151), trata-se de "um certo estado ou condição que adquirem os que se apropriam da nova tecnologia digital e exercem práticas de leitura e de escrita na tela, diferente do estado ou condição - do letramento - dos que exercem práticas de leitura e de escrita no papel."

Considerando o cenário atual, as novas formas de ler o mundo trazem novos questionamentos que transcorrem a circulação e a coexistência de múltiplas linguagens nas mídias sejam elas digitais ou não (ROJO, 2009). Esse desafio estende-se aos 
professores de língua materna ou adicional à medida em que os alunos precisam desenvolver habilidades que dialoguem com a capacidade de produzir e compreender textos que agreguem linguagens diferenciadas e que considerem a pluralidade e a diversidade cultural presentes nesta "multiplicidade de linguagens, semioses e mídias" (ROJO, 2012, p. 8).

Kalantzis et al. (2016) também apontam demandas consequentes das novas mídias e dos novos letramentos na chamada terceira globalização, que possam dialogar com as práticas do eixo intercultural, como a presença de um multilinguismo global que considere as variações linguísticas, a necessidade de explorar a cultura participativa nas novas mídias e a construção de espaços para diversidade cultural e linguística.

Logo, pensando na exploração de práticas que prezam por desenvolver a competência intercultural associada ao uso de novas mídias e tecnologias para o alcance de um ensino de línguas que busque uma cidadania crítica, esta pesquisa concorda com os autores Rocha e Maciel (2013) quando definem esses letramentos digitais de uma forma que posiciona o conceito lado a lado da definição de letramento de crítico:

(...) [uma] participação democrática não pode mais desconsiderar questões
de poder ou os contextos sócio-históricos de produção de culturas e
discursos, incluindo-se os midiáticos. Por esse prisma, os letramentos digitais
podem ser vistos, grosso modo, como modos de pensarmos e dizermos o
mundo pelas lentes das novas tecnologias e mídias, simultaneamente
questionando-as e transformando-as. (ROCHA; MACIEL, 2013, p. 25)

Conforme visto, não é possível dissociar o papel político e de resistência aos discursos e forças hegemônicas de uma educação linguística com um viés intercultural que fomente, através de um letramento crítico, um movimento e um exercício de deslocamento e ruptura. Além disso, conforme Santos (2005, p. 67), “a possibilidade de engendrar o local com o global vem estruturando uma sociabilidade não mais fundada na noção de fixo e enraizado" e, por isso, a formação dos alunos - inclusive e especialmente no ensino de inglês como língua global - precisa contemplar as práticas que já fazem parte de suas rotinas em que exercitam uma "multiplicidade de identidades" nas comunidades on-line.

\section{METODOLOGIA}

Para cumprir com propósitos iniciais deste artigo, foram realizadas pesquisas 
exploratórias da literatura que tem por objetivo familiarizar-se com temas que são pouco explorados. No caso deste artigo, ambos os temas são bastante explorados e pesquisados de forma independente, mas não tão vastamente quando se trata do diálogo natural e necessário que alie as duas temáticas como subjacentes e complementares no âmbito de ensino de língua inglesa.

Assim sendo, os dados mencionados procederam de pesquisas bibliográficas a partir de materiais formulados por meio de livros e artigos publicados em periódicos, a fim de relacionar pontos importantes que percorrem o uso da Internet para a criação de ambientes de prática comunicativa intercultural e de encontrar propostas de atividades que se alinhem com o que foi apresentado com o intuito de melhor entender as particularidades do assunto em questão. Uma vez que o principal verbo que descreve o objetivo da análise qualitativa é compreender, segue-se com esta abordagem para a compreensão da relação da Internet como espaço para atividades interculturais democráticas.

\section{PRÁTICAS INTERCULTURAIS INTERATIVAS: EXEMPLOS}

\subsection{No ensino de idiomas}

Para exemplificar as interseções do uso de espaços digitais para atividades interculturais interativas no ensino de línguas, destaca-se o projeto Teletandem Brasil, desenvolvido pela UNESP, e que tem por objetivo possibilitar a aprendizagem de outras línguas através de junção de pares falantes de diferentes línguas (e, portanto, de culturas distintas também) de forma colaborativa e interativa usando dispositivos de comunicação e a Internet (TELLES; VASSALLO, 2009).

No projeto, os pares se comunicam através de recursos tecnológicos de comunicação, usando aplicativos como Skype ou outros aplicativos que deem suporte para o envio de mensagens, áudios e vídeos sincronicamente. Os participantes realizam a interação entre as duas línguas. A aula é dividida em momentos de interação e mediação, sendo a interação a parte em que os alunos dialogam e se ajudam no processo de aprendizagem seguindo os conceitos de reciprocidades, autonomia e separação de línguas descritas por Telles e Vassallo (2009). Já a mediação trata-se de uma reunião em 
grupo, liderada por alunos de graduação ou pós-graduação, que objetiva falar sobre aspectos relacionados à interação e dúvidas porventura decorrentes da sessão interativa, sejam por problemas acerca de questões linguísticas ou questões culturais.

Essa modalidade de aprendizagem colaborativa que ocorre em espaços on-line de prática deixa naturalmente em evidência o componente cultural entre os participantes, uma vez que negociam as tensões entre o "eu" e o "outro" enquanto estudam, ensinam ou aprendem uma nova língua. Este processo também gera reflexão sobre a própria língua e cultura a partir da interação com o outro.

De forma mais tradicional, a exploração do eixo cultural pode tender para o formato de curiosidades, práticas cotidianas, artefatos, artes ou questões léxicogramaticais. Em interações do tipo Teletandem, o elemento cultural além de estar representado por um indivíduo falante da língua alvo enquanto ambos alternam em posição de aprendizes, a dinâmica se torna recíproca, bilateral e se concretiza em processos de identificação (ou não), de olhar para si, de olhar para o outro e de trabalhar colaborativamente em uma prática comunicativa e interativa.

O projeto ainda está ativo e fica evidente em sua descrição que a mediação, as parcerias para a formação destas comunidades de prática, além de recursos tecnológicos e conectividade são imperativos para o sucesso de dinâmicas similares. Outrossim, as interações do Teletandem permitem encontros interculturais em que auxiliam no desenvolvimento do pensamento crítico, na desconstrução de estereótipos culturais, e que colocam os participantes como protagonistas e como participantes ativos da cultura da língua alvo em um contexto global, além de possibilitar a exploração de recursos tecnológicos e formatos multimodais de comunicação.

Outras atividades similares podem se valer de ferramentas de comunicação síncronas e assíncronas diversas, utilizando recursos que permitam interação, como fóruns online, Wikis, redes sociais como Facebook, Twitter e Instagram, blogs e sites de escrita colaborativa, aplicativos destinados a aprendizagem de idiomas entre pares que ensinam a sua língua materna em troca da aprendizagem da língua do outro, como o Busuu e Tandem.

Este artigo não pretende, no entanto, explicitar o uso dessas ferramentas em detalhes, e sim apontar para rumos que possam fazer os aprendizes de língua inglesa refletirem sobre diversidades linguísticas e culturais, os preparando para compreender 
costumes, hábitos, visões de mundo e de vida diferentes, e fomentando o pensamento crítico sobre suas práticas sociais enquanto falantes de uma língua internacional.

A ideia é que as interações multiculturais em espaços digitais ajudem os alunos a se colocarem como representantes de suas culturas através de suas apresentações, descrições pessoais e seus discursos em geral, possibilitando, dessa forma, o contato com culturas distintas usando a língua inglesa como código comum para se comunicarem.

\subsection{Outro âmbito com o mesmo objetivo}

Um outro projeto, não necessariamente atrelado ao ensino de línguas, mas que marca o uso da internet e seus espaços para o trabalho intercultural, contempla questões importantes e resultados positivos que podem servir de inspiração ou para reflexão a partir de seu modelo, uma vez que busca objetivos similares ao que se tem no debate intercultural dentro da sala de aula idiomas.

Um estudo de 2014 trabalha a formação tecnológica continuada de professores Indígenas e não-Indígenas em uma comunidade virtual e intercultural com foco na interconectividade e colaboração num grupo de estudos no Facebook (BUENO, PANIAGO e SANTOS, 2014). Através da análise dos diálogos e das interações realizadas por meio da rede social mencionada neste parágrafo, as autoras buscam problematizar a interculturalidade e o conectivismo entre os participantes do projeto.

$\mathrm{Na}$ pesquisa de abordagem qualitativa e de cunho etnográfico-virtual, as autoras ressaltam que a atividade resultou na "manutenção de sua identidade, valorização das diferenças, respeito e acolhimento dos contextos plurais e complexos, sentido de coletividade, preservação das culturas, vivência do diálogo e aprendizagem continuada" (BUENO, PANIAGO \& SANTOS, 2014, p. 1363). Segundo elas, o grupo participante do projeto considera a escola como um "espaço sociocultural marcado por crenças, saberes, culturas, conflitos, desafios, os quais evidenciam diferentes contextos subjetivos, sociais, plurais e complexos" (BUENO, PANIAGO \& SANTOS, 2014, p. 1363).

\section{CONSIDERAÇÕES NÃO-FINAIS}


Mediante o exposto, deve-se refletir que, para proporcionar interações plurais e multiculturais, professores de inglês podem se valer da Internet para criar espaços online de comunicação síncronas e assíncronas, considerando que a Web possibilita fluxos sociais e a comunicação entre diferentes pessoas de culturas distintas de forma mais acessível. No entanto, não se deve negligenciar o fato de que é desafiador para o professor encontrar meios de combinar estratégias para atrelar a instrução de sala de aula com as tantas oportunidades que os alunos têm acesso formalmente e informalmente. Isso reforça a necessidade de um letramento crítico e digital que pode, e deve, ser trabalhado através de práticas interativas interculturais.

Quanto às implicações didático-pedagógicas, ao pensar e planejar as atividades e dinâmicas para o eixo intercultural, os alunos precisam ser preparados para encontros multiculturais em que irão desenvolver o pensamento crítico, desconstruir estereótipos, colocar-se como protagonistas e como participantes da cultura da língua alvo em um contexto global, além de explorar recursos tecnológicos e formatos multimodais de comunicação, como visto em um dos exemplos citados (Teletandem Brasil).

A Internet e as novas formas de comunicação funcionam, de certa forma, como um fórum em que pessoas de diferentes "culturas" podem se encontrar. Experiências, projetos e estudos, como os dois descritos aqui, mostram resultados que dialogam com as questões na revisão da literatura mencionadas neste trabalho. Para estudos posteriores, sugere-se aprofundar-se em como a educação linguística está se valendo desses espaços digitais para mediação da comunicação com aspectos interculturais e em como os professores estão preparados para planejar e mediar estas dinâmicas.

Para concluir, este artigo deixa para impulsionar o pensamento acerca da prática do professor de inglês a definição de "voz" em Bakhtin (1981). Na visão do autor, tratase de uma das formas através da qual as pessoas (os aprendizes de uma "língua do mundo", neste caso), por meio da linguagem, se posicionam socialmente, culturalmente e ideologicamente. E, assim, há uma dimensão de grande impacto social e cultural do ensino de uma língua com status de língua internacional, convergindo o papel do professor de inglês e das atividades que propõe (incluindo aquelas em espaços digitais plurais e multiculturais) em um ato político na busca de um futuro global mais inclusivo e mais tolerante. 


\section{Referências}

ALMEIDA FILHO, J.C.P. "Língua além de cultura ou além da cultura, língua? Aspectos do ensino da interculturalidade." In: CUNHA, M.J.C \& SANTOS, P. Tópicos em Português Língua Estrangeira. Brasília: Editora Universidade de Brasília, 2002, p.209-215.

BAKHTIN, M. Problemas da poética de Dostoiévski. Trad. Paulo Bezerra. Rio de Janeiro: Forense-Universitária, 1981.

BARBOSA, L.M.A. "Visões interculturais ou identidades cristalizadas? O Brasil e os brasileiros nos livros didáticos de português para estrangeiros." In: Fleuri, R.M.(Org.). XII Congresso da Associação Internacional para pesquisa Intercultural (ARIC), v. 1, 2009, p. 1-18.

BUENO, M. O. B; PANIAGO, M. C. L. e SANTOS, R. M.R. Formação Continuada de Professores em Conexões Interculturais no Facebook: Pluralidade de Sentidos e Significados sobre Tecnologias e Educação. Revista e-Curriculum, São Paulo, v. 02, n. $12,1348-1365,2014$.

CORBETT, J. Intercultural Language Activities. Cambridge Handbook for Teachers. Cambridge: CUP, 2010.

CRYSTAL, D. English as a global language. Cambridge: Cambridge University Press, 2003

KALANTZIS, M; COPE, B.; CHAN, E.; DALLEY-TRIM, L. Literacies. Cambridge: Cambridge University Press, 2016.

KAWACHI, G.J. Estereótipos culturais em estágios avançados de aprendizado de inglês como língua estrangeira e seus desdobramentos para ensino e uso do idioma. Dissertação (Mestrado em Linguística) - Universidade Federal de São Carlos, São Carlos, 2011.

KRAMSCH, C. Language and Culture. Oxford: Oxford University Press, 1998.

KUMARAVADIVELU, B. "A Linguística Aplicada na Era da Globalização." In: MOITA-LOPES, L.P. (Org.). Por uma Linguística Aplicada Indisciplinar. São Paulo: Parábola Editorial, 2006. p. 129-148.

KUMARAVADIVELU, B. Cultural Globalization and Language Education. New Haven/London: Yale University Press, 2008.

LIMA, A. P.; KAWACHI, G. J. "Ensino de inglês para crianças da era da globalização: reflexões sobre (multi)letramentos, formação de professores e educação", In: ROCHA, C. R.; BRAGA, D.B.; CALDAS, R. R.(Orgs.) Políticas linguísticas, ensino de línguas e 
formação docente: desafios em tempos de globalização e internacionalização. Campinas: Pontes Editores, v. 11, 2015, p. 195-213.

MALDONADO-TORRES, N. “A tipologia do ser e a geopolítica do conhecimento.” In: SOUSA SANTOS B.; MENEZES, M. P. (Orgs.) Epistemologias do Sul. São Paulo: Cortez, 2010, p. 396-433.

MOITA-LOPES, L. P. Oficina de linguística aplicada: a natureza social e educacional dos processos de ensino/aprendizagem de línguas. São Paulo: Mercado de Letras, 1996.

MOITA-LOPES, L. P. Inglês e globalização em uma epistemologia de fronteira: ideologia linguística para tempos híbridos. DELTA, São Paulo, v. 24, n. 2, 2008, p. 309340 .

PAIVA, V.L.M.O. O uso da tecnologia no ensino de línguas estrangeiras: breve retrospectiva histórica. 2008. Disponível em: http://www.veramenezes.com/techist.pdf. Acesso em 07 ago. 2020.

RAJAGOPALAN, K. O inglês como língua internacional na prática docente: In: Lima, Diógenes Cândido. (ed.). Ensino e Aprendizagem de Língua Inglesa: Conversas com Especialistas. São Paulo: Parábola Editorial, 2009, p. 39-46

RAJAGOPALAN, K. Por uma Linguística Crítica: linguagem, identidade e a questão ética. São Paulo: Parábola Editorial, 2003.

ROCHA, C. H.; MACIEL, R. F. "Língua Estrangeira, Formação Cidadã e Tecnologia: ensino e pesquisa como participação democrática." In: ROCHA, C. H..; MACIEL, R. F. (Orgs.). Língua estrangeira e formação cidadã: por entre discursos e práticas. Campinas: Pontes Editores, 2013, p. 13-30.

ROJO, R. Letramentos múltiplos, escola e inclusão social São Paulo: Parábola Editorial, 2009.

ROJO, R.; MOURA, Eduardo. Multiletramentos na escola. São Paulo: Parábola Editorial, 2012, p.8-12

SANTOS, E. Educação online: cibercultura e pesquisa-formação na prática docente.2005. 351 fl. Tese (Doutorado em Educação) - Faculdade de Educação da Bahia. Universidade Federal da Bahia, Salvador.

SILVA, M. Educar na Cibercultura: Desafios à formação de professores para docência em cursos online. Revista Digital de Tecnologias Cognitivas, São Paulo, n. 3, p. 36-51, 2010

SILVA, M. Sala de aula interativa. 6. ed. São Paulo: Edições Loyola, 2012.

SILVA, M. Falta interatividade. Revista Carta na Escola, São Paulo, p.1, 2011. Disponível em: https://www.cartacapital.com.br/educacao/falta-interatividade. Acesso 
em 20 de novembro de 2017.

SOARES, M. Novas práticas de leitura e escrita: letramento na cibercultura. Educação e Sociedade, Campinas, v. 23, n. 81, p. 143-160, 2002.

VASSALLO, M. L.; TELLES, J. A. "Ensino e aprendizagem de línguas em tandem: princípios teóricos e perspectivas de pesquisa." In: TELLES, J. A. (Org.). Telet@andem: um contexto virtual, autônomo e colaborativo para aprendizagem de línguas estrangeiras para o século XXI. Campinas: Pontes, 2009, p 21-29.

Recebido em: 30/08/2020

Aceito em: 10/10/2020 